\title{
Gegraphy
}

\section{As Temporal as Spatial: It Is Geographical - Exploring Spatio-temporality in Modelling the Risk of Climate Change and Natural Hazards}

\author{
Stig H. Jørgensen, Wouter J. W. Botzen \& Lena Sanders
}

To cite this article: Stig H. Jørgensen, Wouter J. W. Botzen \& Lena Sanders (2017) As Temporal as Spatial: It Is Geographical - Exploring Spatio-temporality in Modelling the Risk of Climate Change and Natural Hazards, Norsk Geografisk Tidsskrift - Norwegian Journal of Geography, 71:1, 60-61, DOI: 10.1080/00291951.2017.1287773

To link to this article: https://doi.org/10.1080/00291951.2017.1287773

\section{曲 Published online: 28 Feb 2017.}

\section{Submit your article to this journal $๘$}

Џ Article views: 33

Q View related articles ¿

View Crossmark data $\widetilde{\nearrow}$ 


\section{Doctoral Thesis Review - Anmeldelse av doktoravhandling}

Khakpour, Mehdi. 2015. As Temporal as Spatial: It Is Geographical - Exploring Spatio-temporality in Modelling the Risk of Climate Change and Natural Hazards. Thesis for the degree of Philosophiae Doctor, Trondheim, December 2015. Norwegian University of Science and Technology, Faculty of Social Science and Technology Management, Department of Geography. Doctoral Theses at NTNU 2015:302. Trondheim: NTNU. 147 pp. ISBN 978-82-326-1260-4 (printed), ISBN 97882-326-1261-1 (electronic), ISSN 1503-8181.

This thesis is highly relevant for at least two main reasons. First, problems of higher natural hazard risks resulting from climate change problems are already materializing. Second, a few years ago a Nordic expert panel's evaluation of research in geography in Norway pointed out in the summary of its report that development of quantitative methods and 'the handling of large datasets in the discipline should be improved' (Research Council of Norway 2011, 9). To a great extent, Mehdi Khakpour's thesis meets these challenges.

From a thematic point of view, the main aim of the thesis is to study the risk of natural hazards and to take into account geographical local variations. From a conceptual and methodological point of view, the aim is to show Khakpour's interest in modelling approaches that take into account space and time at a fine resolution.

The thesis consists of three articles:

Article I: Khakpour, M. \& Rød, J.K. 2016. An attractionbased cellular automation model for generating spatiotemporal population maps in urban areas. Environment and Planning B: Planning and Design 43, 297-319.

Article II: Khakpour, M., Berthling, I. \& Rød, J.K. Modelling the risk of climate change and natural hazard damage by accounting for local variations with a geographically weighted regression. (not submitted for publication)

Article III: Khakpour, M., Rød, J.K. \& Berthling, I. Normalizing natural hazards damage based on vulnerability and exposure factors on the municipality level. (not submitted for publication)

In addition to the articles, the thesis contains a synthesizing superstructure, headed 'Comprehensive Summary', which comprises subsections headed 'Terminology and Theoretical Issues' related to risk, space, and time, and 'Methods and
Material', which includes a general methodological discussion. Two research questions assert that taking into account space and time at a fine resolution improves the modelling and the understanding of the risk of natural hazards. A third question is more methodological-oriented and concerns the difference in the role of spatio-temporality in two methodological domains: spatial statistical models (Article II) and automaton-based models (Article I). The aim of comparing the implementation of spatio-temporality in these two methodological domains is mentioned. However, Khakpour's work has a stronger focus on possibilities than limitations and uncertainties in modelling and adjusting for spatio-temporal natural disaster risk.

Regarding concepts and theories, a conceptualization of risk as a product of exposure, hazard, and vulnerability is clearly illustrated in the thesis. Each article focuses on two of the three components of risk: vulnerability and exposure (Article I), vulnerability and hazard (Article II), and hazard and exposure (Article III). The concept of spatio-temporality is applied throughout the thesis and is at the core of the research questions.

Article I studies a cellular automata model that was developed to present population maps and was geosimulated for the city of Trondheim, Norway. Based on fine spatial and temporal resolutions, the method illustrates the variation in the distribution of population in the city at various risk levels throughout a 24 -hour period. The article shows that the model can be used to estimate population at risk in the wake of major disasters in an urban area at any time of the day. The model and resulting maps identify other essential information, such as movement patterns and population activity levels, which can be applied for public safety and transport modelling.

Article II presents global regression models for the continuous dependent variable of the intensity of insured natural disaster damage in Norway, negative binomial regression (NBR) models of the count of insured damages, and geographically weighted regression models. The latter are more locally adapted and include 64 socio-economic, geomorphological, and climate-related variables for the 428 Norwegian municipalities. Observations covered a period of 33 years (1980-2012). The authors of Article II deal with the important issues of collinearity problems. Findings from the global models indicate that damage intensity is significantly related to climatic anomalies, vulnerability factors, and flood exposure. The NBR results show that the frequency of damage events is associated 
with exposures to strong winds and other extreme climatic events.

Article III aims to develop a methodology for normalization of natural hazards damage, which the authors call VulExpo. An extensive review of normalization methodologies for natural hazards is presented and the authors compare the performance of previously used methods with the VulExpo method. The latter method employs the product of vulnerability, exposure, and hazard as the approach to normalize data on reported damage to the insured properties in Norway. The authors argue that this normalization method seems superior to several other widely used normalization methods.

There are reasons to question how the assumed relations between losses on the one hand, and exposure and vulnerability indicators on the otherhand, can be related to the empirical findings in Article II. In Article II, the authors estimate such relations empirically, but do not clearly explain why these relations are not used for the normalization conducted in Article III, instead of assuming relations. In Article III, the results are well presented in graphs. A clear interpretation and discussion of these findings is hampered by some unclear issues in the methods section of the article. The conclusions presented in Article III give a sound understanding of the related findings on normalizing natural hazards damage at the municipality level. The analyses could have given rise to some critical reflection on the work performed, in terms of potential biases or uncertainties in operationalizations and modelling. Alternatively, there could have been a discussion of various model assumptions or omitted variables.

The main title of the thesis, As Temporal as Spatial: It Is Geographical, is highly relevant considering climate change and extreme weather events and reflects the author's interest in spatio-temporality. The overarching importance of examining spatio-temporal dimensions when assessing natural disaster risk and disaster risk management is relevant and brings new knowledge to this discipline. Khakpour points out that many risk assessments are done on a spatially aggregate level, whereas natural disaster risk are locally determined. Moreover, most previous studies neglected some relevant temporal dimensions, such as populations exposed to hazards at different times of the day, but these dimensions are examined in this thesis.

Regarding the methodology and technical aspects, the thesis is ambitious. Khakpour mobilizes two families of methods: (1) computational models as cellular automata for dealing with spatial dynamics, and (2) advanced empirical statistical methods, such as geographically weighted regressions for dealing with the non-stationarity of relations in space and normalization of trend analysis. A strong point of the thesis is the combination of expertise in statistical and computational domains. It would have been interesting to read about the differences between the proposed models and the existing ones that have been reported in the literature, both in terms of their application potential and to know the sensitivity of Mehdi Khakpour's results against the level of information. All things considered, the thesis represents an important contribution to modelling environmental risk and gives further insights into the application of time and space in this research field.

\section{Reference}

Research Council of Norway. 2011. Geography Research in Norway: An Evaluation. Oslo: The Research Council of Norway, Evaluation Division for Science.

Stig H. Jørgensen

Department of Geography, Norwegian University of Science and Technology, NO-7491 Trondheim, Norway

Wouter J. W. Botzen

Department of Environmental Economics, Institute for Environmental Studies (IVM), VU, University Amsterdam, De Boelelaan 1105, NL-1081 HV Amsterdam, Netherlands

Lena Sanders

Laboratory Géographie-cités, 13 rue du Four, FR-75006, Paris, France

(c) 2017 S. H. Jørgensen, W. J. W. Botzen \& L. Sanders http://dx.doi.org/10.1080/00291951.2017.1287773

Editors: Kerstin Potthoff, Catriona Turner Check for updates 